\title{
Separation and analysis of Monascus yellow pigment produced on durian seed substrate
}

\author{
*Srianta, I., Nugerahani, I. and Ristiarini, S. \\ Department of Food Technology, Faculty of Agricultural Technology, Widya Mandala Catholic University \\ Surabaya, Jalan Dinoyo 42-44 Surabaya, Indonesia 60265
}

\author{
Article history: \\ Received: 15 January 2020 \\ Received in revised form: 2 \\ March 2020 \\ Accepted: 5 March 2020 \\ Available Online: 27 March \\ 2020
}

\section{Keywords:}

Monascus,

Yellow pigment,

Durian seed,

Separation,

Analysis

\begin{abstract}
This research was aimed to separate and analyse Monascus yellow pigment (MYP) with chromatography. MYP was in a mixture with red and orange pigments. MYP separation was performed in a silica gel column with eluent of ethyl acetate: ethanol: water $=90: 25$ : 4. The separated MYP were then subjected to analysis by using spectrophotometer, TLC, LC-PDA and LC-MS/MS. The results revealed that the separated MYP has a maximum absorption at $386 \mathrm{~nm}$. Out of five MYP compounds detected by using LC-MS/MS, two of them were well known yellow pigment compounds, monascin and ankaflavin. Monascin and yellow II were the major pigment compounds in MYP.
\end{abstract}

DOI:

https://doi.org/10.26656/fr.2017.4(4).020

\section{Introduction}

Monascus pigments are secondary metabolites of Monascus fungi biosynthesized through the polyketide pathway. It has been used as a natural food colourant, food supplement, and in traditional medicine. Monascus pigments consist of many pigment compounds which are categorized into three groups i.e. red, orange and yellow pigments. A total of six well-known pigment compounds are monascorubramine and rubropunctamine (red pigments), monascorubrin and rubropunctatin (orange pigments), monascin and ankaflavin (yellow pigments) (Feng et al., 2012; Srianta et al., 2014; Agboyibor et al., 2018). Until 2011, thirty-nine new pigment compounds have been identified (Feng et al., 2012).

Rice is commonly used as solid-state fermentation substrate in Monascus pigments production. Non-rice substrates have been developed in the Monascus pigment production e.g. corn, adlay, sorghum, dioscorea, jackfruit seed and durian seed (Pattanagul et al., 2007; Babitha et al., 2007; Hsu et al., 2011; Srianta et al., 2012; Srianta et al., 2016). Our previous studies revealed that Monascus purpureus produced red, orange and yellow pigments. Exploration of Monascus yellow pigments is still limited. MYP is not only a potential natural colourant for biscuit, mayonnaise, wheat noodle, etc. (Srianta et al., 2014) but also as functional food ingredient and in medicine, because MYP has various positive health effects i.e. antioxidant, antidiabetes and anticancer (Hsu et al., 2011; Chen and $\mathrm{Wu}, 2016$ ). Monascin and ankaflavin have antitumor activity (Akihisa et al., 2005; Su et al., 2005), antiobesity activity, anti-atherosclerosis effect (Wang et al., 2013; Liu et al., 2018), improve memory and learning ability (Lee et al., 2015). Chen and $\mathrm{Wu}$ (2016) reported that MYPs have promising potential for application in food and pharmaceutical industries based on their bioactivities.

Silica gel has been applied in Monascus pigments mixture separation through thin layer chromatography and column chromatography systems with various eluents i.e. chloroform, methanol, benzene, acetone and petroleum ether (Kim et al., 2006; Vidyalakshmi et al., 2009; Hsu et al., 2011; Lee et al., 2011). In practice, ethyl acetate, ethanol and water are often more preferred for food and pharmaceutical processing compared to other solvents due to their safety and affordability. HPLC is utilized to analyze various Monascus pigments because of its high sensitivity and multiple detection systems including ultraviolet, fluorescent, photodiode array and mass spectrometer detectors (Feng et al., 2012).

This research was aimed to separate and analyse MYP produced on durian seed substrate. This is the first 
investigation in MYP separation using ethyl acetate, ethanol and water.

\section{Materials and methods}

\subsection{Microorganism, substrate and chemicals}

Monascus purpureus M9 culture was used in the solid-state fermentation on durian seed substrate. The culture was maintained periodically on Potato Dextrose Agar. Durian seed was obtained from a durian processing unit in Surabaya (Indonesia). The durian seed is a by-product of the food industry and was used as the SSF substrate. All chemicals were chromatographic and analytical grades.

\subsection{Pigments production through solid-state} fermentation with durian seed substrate

Pigments production was performed through solidstate fermentation on durian seed substrate according to our previous research (Srianta et al., 2012). After peeling, cutting, soaking, sterilization at $121{ }^{\circ} \mathrm{C}$ for 10 mins and cooling, the durian seed substrate was inoculated with Monascus purpureus starter culture, and then incubated at $30^{\circ} \mathrm{C}$ for 14 days. The fermented matter was dried at $45^{\circ} \mathrm{C}$ for $24 \mathrm{hrs}$, ground and sieved.

\subsection{Monascus pigment separation}

The Monascus pigment was extracted with soxhletation method in ethanolic solvent at a ratio of 1:50 for 2 hrs. The extract was then evaporated in a rotary evaporator. The evaporated extract was subjected to separation process. MYP separation was performed in a column chromatography ( $10 \mathrm{~mm} \times 500 \mathrm{~mm})$ with silica gel 60 . The column was packed with silica gel by slurry method, then pre eluted with ethyl acetate: ethanol: water $=90: 25: 4$. The extract was put into the column and eluted with ethyl acetate: ethanol: water $=90: 25: 4$. The obtained fractions were subjected to analysis by using TLC and spectrophotometer. The MYP fraction was analyzed the pigment composition by using LC-MS/MS.

\subsection{Pigment analysis}

The separated pigments were subjected to the TLC analysis according to Nimnoi and Lumyong (2011) with modification, on silica gel F60 plate, with ethyl acetate: ethanol: water at 90:25:4. The separated MYP was scanned in a range of wavelength $380-600 \mathrm{~nm}$ with UVVis spectrophotometer (Shimadzu UV-1900, Japan). Pigment composition analysis was conducted by using LC-MS/MS (Shimadzu, Kyoto, Japan) with Q1 scan positive mode and SIM positive mode. The extract was filtered through a $0.2 \mu \mathrm{m}$ PTFE filter membrane, put on to the autosampler. Pigments were separated on a Cosmosil 5 C18-MS-II (4.6 i.d. x $150 \mathrm{~mm}$ ) column, with an isocratic program of mobile phase consists of acetonitrile containing $0.1 \%$ formic acid and water containing $0.1 \%$ formic acid $(60: 40 \mathrm{vol} / \mathrm{vol})$, flow rate of $0.5 \mathrm{~mL} / \mathrm{min}$; oven temperature of $40^{\circ} \mathrm{C}$, run time for 30 min. Pigment compounds were detected by MS/MS using electro-spray ionization in the positive ion mode, scan range: $\mathrm{m} / \mathrm{z} 100$ to 1000 .

\section{Results and discussion}

In the separation of the pigments by using column chromatography, 4 fractions (F1 F2, F3 and F4) with different colours have been derived. The first fraction was MYP target, while other fractions were orange and red pigments. The MYP has the highest retention factor, followed by F2, F3 and F4. Those fractions and pigments profile on TLC shown in Figure 1. Those profiles describe that MYP was the pigments with the lowest polarity among the others. Although the chemical structure of Monascus pigments consists of $\beta$-ketoacid and chromophore, MYP compounds contain less polar groups than those of red pigments. The presence of $-\mathrm{NH}_{3}$ group can increase the polarity of red pigments.

F1 $\quad$ F2 $\quad$ F3 $\quad$ F4

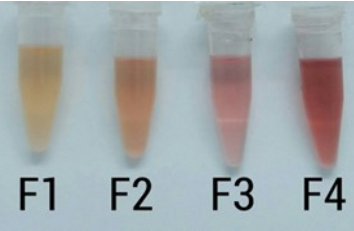

(A)
(B)

Figure 1. Picture of 4 separated fractions of Monascus pigments (A) and their TLC chromatogram (B). F1: Fraction 1; F2: Fraction 2; F3: Fraction 3; F4: Fraction 4.

Figure 2 shows the fractions scanning by using spectrophotometer at $380-700 \mathrm{~nm}$. F1, the MYP, has a $\lambda$ max at $386 \mathrm{~nm}$ that was in yellow spectrum. F3 and F4 have 2 peaks in the orange and red spectrum. Those reflect that contain a mixture of orange and red pigments. This is the first investigation on the pigment compounds composition of MYP by using the LC-MS/MS. The LCMS chromatograms and pigment composition of the extracts are presented in Figure 3 and Table 1, respectively. Five MYP compounds were detected by using LC-MS/MS i.e. monascin, ankaflavin, xanthomonasin B, monascopyridine B and Yellow II. 


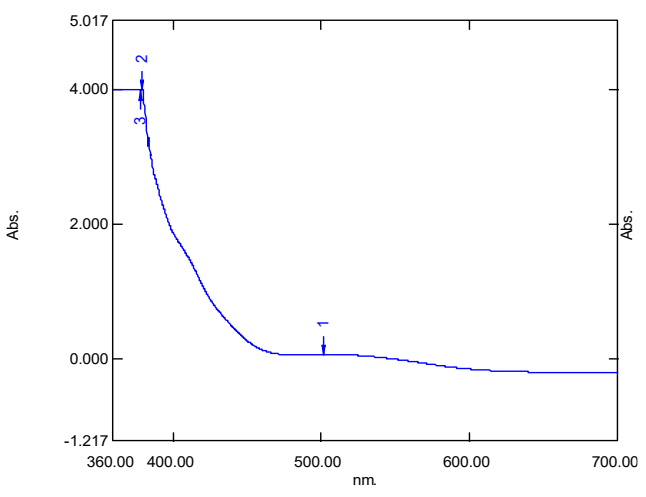

F1

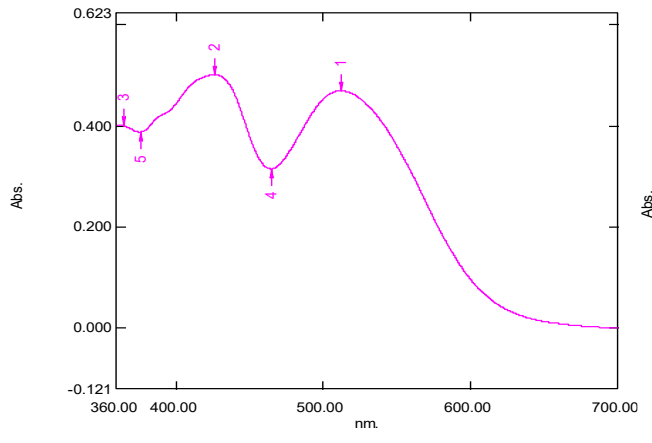

F3

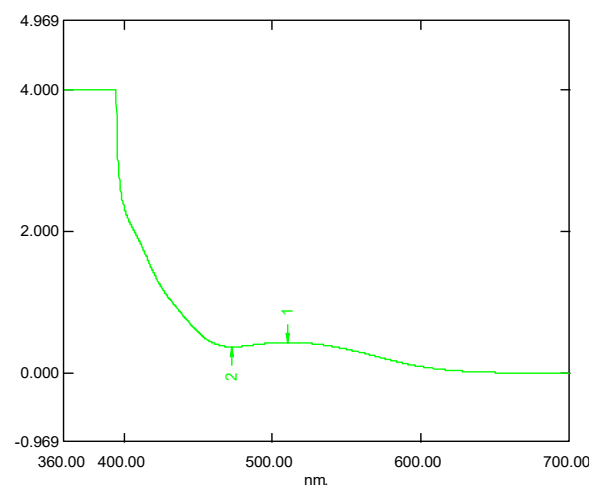

F2

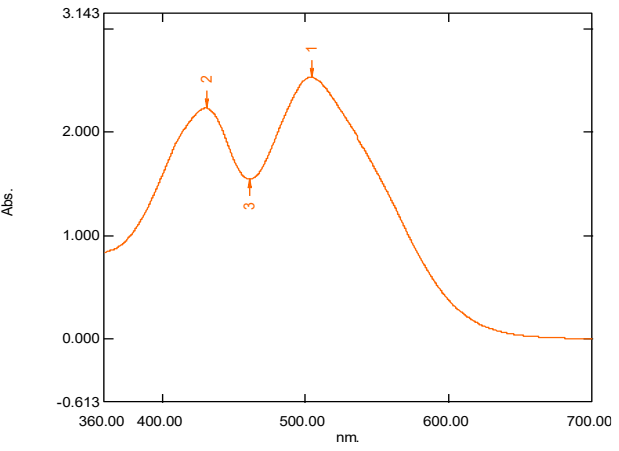

F4

Figure 2. Scanning results of separated Monascus pigment fractions by using spectrophotometer. F1: Fraction 1; F2: Fraction 2; F3: Fraction 3; F4: Fraction 4.
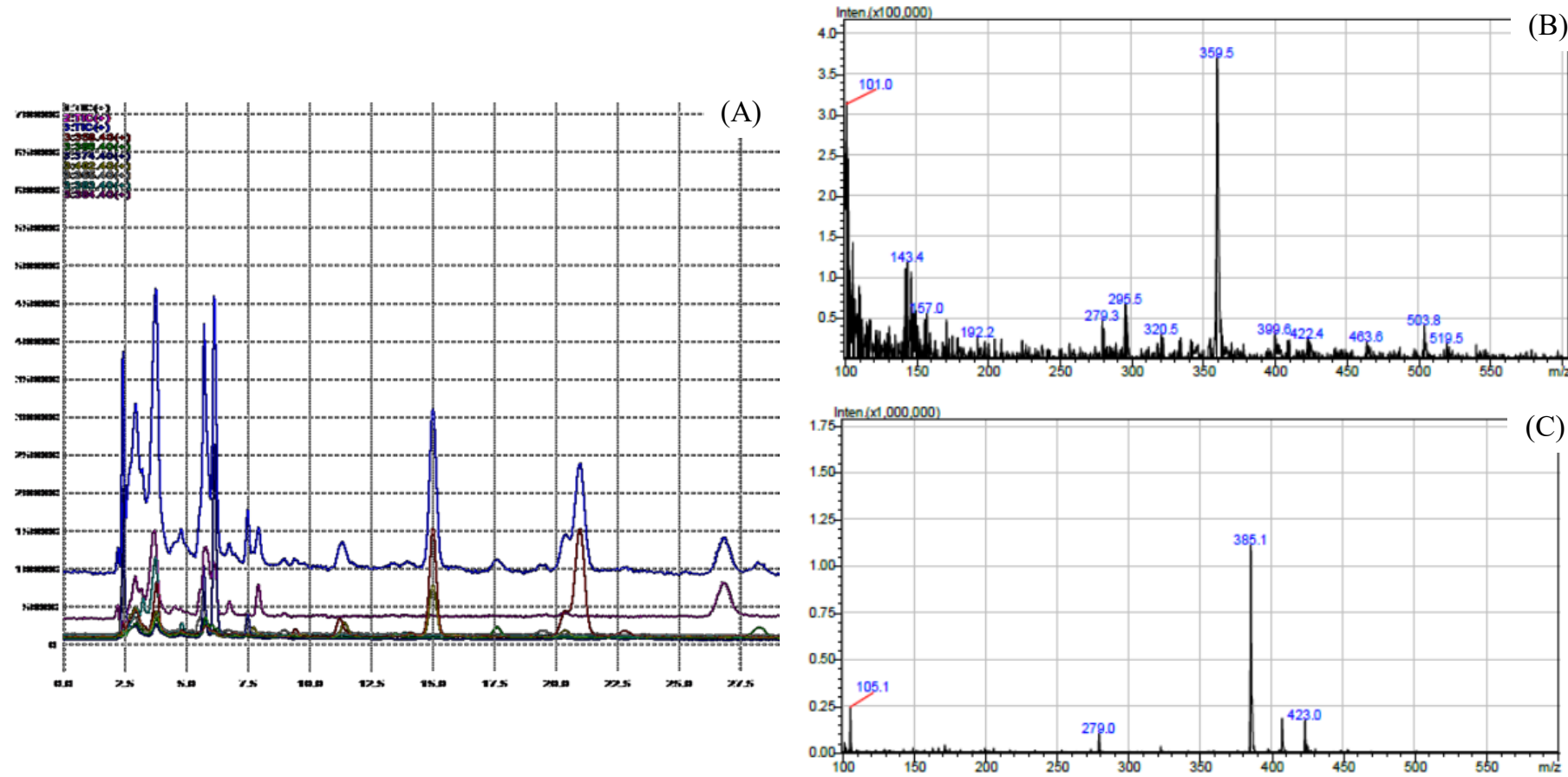

Figure 3. LC-MS analysis results: Total Ion Chromatogram of MYP (A) and representatives of the chromatogram of major MYP monascin (B) and yellow II (C).

Table 1. MYP composition

\begin{tabular}{cc}
\hline MYP compound & Content (\%) \\
\hline Monascin & 59.81 \\
Ankaflavin & 6.32 \\
XanthomonasinA & n.d. \\
XanthomonasinB & 0.67 \\
Monascopyridin A & n.d. \\
Monascopyridin B & 5.39 \\
Yellow II & 27.80 \\
\hline
\end{tabular}

n.d. $=$ not detected 
Monascin and Yellow II were the major pigment compounds in the MYP with the relative amount of $59.81 \%$ and $27.80 \%$, respectively The MYP composition depends on the pigment composition in Monascus Fermented Durian Seed (MFDS), extraction and separation processes.

Pigments in MFDS produced through a complex polyketide biosynthesis pathway in the Monascus fungi, but it is still unclear and controversy. Some researchers proposed that only orange pigments (rubropunctatin and monascorubramine) were biosynthetic, and the others were transformed from them chemically. In orange pigment rubropunctatin biosynthesis, it consist of the $\beta$ ketide pathway to form acetate and malonate and another pathway to form n-hexanoyl acetyl residue. Yellow pigments can be transformed from orange pigments via oxidation. Our previous research revealed that solvent type affected the Monascus pigment composition. The ethanolic extract contains higher MYP than those in the mixture solvent of ethanol and water. This research used ethanol as the extraction solvent. In the separation process, the chromatographic system used has successfully separated MYP from the red and orange pigments.

Monascin, the major MYP compound in this research, is attractive for its strong bioactivities such as anticancer, antitumor, antidiabetic, antioxidative stress, antiinflammatory, antiobesity and showed antiatherogenic activities, and also improves memory and learning ability. On the other hand, there is no report on the yellow II bioactivity.

\section{Conclusion}

The MYP has been successfully separated in a column chromatography packed with silica gel 60 and eluent of ethyl acetate:ethanol:water=90:25:4. Five MYP compounds have been detected by using LC-MS/MS i.e. monascin, ankaflavin, xanthomonasin B, monascopyridine B and yellow II. Monascin and yellow II were the major pigment compounds in MYP.

\section{Conflict of Interest}

The authors declare no conflict of interest.

\section{Acknowledgments}

This work was supported by Direktorat Riset dan Pengabdian Masyarakat, Direktorat Jenderal Penguatan Riset dan Pengembangan, Kementerian Riset, Teknologi, dan Pendidikan Tinggi, Republik Indonesia through the scheme of Penelitian Dasar Unggulan Perguruan Tinggi (PDUPT) 2019 [contract number 200X/WM01.5/
$\mathrm{N} / 2019]$.

\section{References}

Agboyibor, C., Kong, W.B., Chen, D., Zhang, A.M. and Niu, S.Q. (2018). Monascus pigments production, composition, bioactivity and its application: A review. Biocatalysis and Agricultural Biotechnology, 16, 433-447. https://doi.org/10.1016/ j.bcab.2018.09.012

Akihisa, T., Tokuda, H., Yasukawa, K., Ukiya, M., Kiyota, A., Sakamoto, N., Suzuki, T., Tanabe, N. and Nishino, H. (2005). Azaphilones, furanoisophthalides, and amino acids from the extracts of Monascus pilosus-fermented rice (redmold rice) and their chemopreventive effects. Journal of Agricultural and Food Chemistry, 53, 562 -565. https://doi.org/10.1021/jf040199p

Babitha, S., Soccol, C.R. and Pandey, A. (2007). Solidstate fermentation for the production of Monascus pigments from jackfruit seed. Bioresource Technology, 98(8), 1554-1560. https:// doi.org/10.1016/j.biortech.2006.06.005

Chen, G. and Wu, Z. (2016). Production and biological activities of yellow pigments from Monascus fungi. World Journal of Microbiology and Biotechnology, 32, 136. https://doi.org/10.1007/s11274-016-2082-8

Feng, Y., Shao, Y. and Chen, F. (2012). Monascus pigments. Applied Microbiology and Biotechnology, 96, 1421-1440. https://doi.org/10.1007/s00253-0124504-3

Hsu, Y.W., Hsu, L.C., Liang, Y.H., Kuo, Y.H. and T.M. Pan. (2011). New bioactive orange pigments with yellow fluorescencefrom Monascus-fermented dioscorea. Journal of Agricultural and Food Chemistry, 59, 4512-4518. https://doi.org/10.1021/ jf1045987

Kim, C., Jung, H., Kim, Y.O. and Shin, C.S. (2006). Antimicrobial activities of amino acid derivatives of Monascus pigments. FEMS Microbiology Letters, 264(1), 117-124. https://doi.org/10.1111/j.15746968.2006.00451.x

Lee, B.H., Hsu, W.H., Liao, T.H. and Pan, T.M. (2011). The Monascus metabolite monascin against TNF- $\alpha$ induced insulin resistance via suppressing PPAR- $\gamma$ phosphorylation in $\mathrm{C} 2 \mathrm{C} 12$ myotubes. Food and Chemical Toxicology, 49(10), 2609-2617. https:// doi.org/10.1016/j.fct.2011.07.005

Lee, C.L., Lin, P.Y., Hsu, Y.W. and Pan, T.M. (2015). Monascus-fermented monascin and ankaflavin improve the memory and learning ability in amyloid $\beta$-protein intracerebroventricular-infused rat via the suppression of Alzheimer's disease risk factors. Journal of Functional Foods, 18(Part A), 387-399. 
https://doi.org/10.1016/j.jff.2015.08.002

Liu, L., Zhao, J., Huang, Y., Xin, Q. and Wang, Z. (2018). Diversifying of chemical structure of native Monascus pigments. Frontiers in Microbiology, 9, 3143. https://doi.org/10.3389/fmicb.2018.03143

Nimnoi, P. and Lumyong S. (2011). Improving solidstate fermentation of Monascus purpureuson agricultural products for pigment production. Food Bioprocess and Technology, 4, 1384-1390. https:// doi.org/10.1007/s11947-009-0233-8

Pattanagul, P., Pinthong, R., Phianmongkhol, A. and Leksawasdi, N. (2007) Review of angkak production (Monascus purpureus). Chiang Mai Journal of Science, 34, 319-328.

Srianta, I., Hendrawan, B., Kusumawati, N. and Blanc, P.J. (2012). Study on durian seed as a new substrate for angkak production. International Food Research Journal, 19(3), 941-945.

Srianta, I., Ristiarini, S., Nugerahani, I., Sen, S.K., Zhang, B.B., Xu, G.R. and Blanc, P.J. (2014). Recent research and development of Monascus fermentation products. International Food Research Journal, 21(1), 1-12.

Srianta, I., Zubaidah, E., Estiasih, T., Yamada, M. and Harijono (2016). Comparison of Monascus purpureus growth, pigment production and composition on different cereal substrates with solid state fermentation. Biocatalysis and Agricultural Biotechnology, 7, 181-186. https://doi.org/10.1016/ j.bcab.2016.05.011

Su, N.W., Lin, Y.L., Lee, M.H. and Ho, C.Y. (2005). Ankaflavin from Monascus fermented red rice exhibits selective cytotoxic effect and induces cell death on Hep G2 cells. Journal of Agricultural and Food Chemistry, 53, 1949-1954. https:// doi.org/10.1021/jf048310e

Vidyalakshmi, R., Paranthaman, R., Murugesh, S. and Singaravadivel, K. (2009). Microbial bioconversion of rice broken to food grade pigments. Global Journal of Biotechnology and Biochemistry, 4, 84 87.

Wang, L.C., Lung, T.Y., Kung, Y.H., Wang, J.J., Tsai, T.Y., Wei, B.L., Pan, T.M. and Lee, C.L. (2013). Enhanced anti-obesity activities of red mold dioscorea when fermented using deep ocean water as the culture water. Marine Drugs, 11(10), 3902-3925. https://doi.org/10.3390/md11103902 